Abace, Ltd., in introducing two new crops (cocoa and oil palms). The report also stresses the way in which opportunities are taken for partnership with private industry and association with local interests, and apart from stressing the importance of public relations and encouraging both at home and overseas a correct understanding of the Corporation's purpose and work, the report contains two interesting sections discussing various aspects of management and training schemes which merit separate consideration.

\title{
ECHO-SOUNDING EXPERIMENTS IN THE BARENTS SEA
}

\begin{abstract}
$\mathrm{N}^{\mathrm{h}}$ EARLY all large fishing vessels carry echo. sounders for locating fish. A 'ping' of sound is sent down into the water, and any fish betwcen the ship and the sea bed give echoes which can be detected. In the case of vessels trawling for cod, it is fish within a few fathoms of the sea bed which are of interest, and because of the short separation in time between the echoes from these and the much stronger echo from the sea bed, certain difficulties arise. These have to a large extent been overcome by displaying the echoes on a cathode-ray oscilloscope, arranged to present echoes from near the sea bed on an expanded scale.

A recent booklet contains five papers concerned with the use of such equipment*. They cover the identification and measurement of the echoes, the rolationship of the number and size of echoes to the catch of fish, the measurement of the strength of echoes from individual fish, practical and theoretical work on the properties of the equipment, and its use for surveying the distribution of fish on the fishing grounds. Taken together, they form a comprehensive survey of the characteristics and use of the equipment considered primarily from a prectical point of view.

One is particularly struck by the high correlation between the count of echo signels, that is, the sum of the strengths of each echo during a trawling run, corrected for depth, and the number of fish caught. The correlation coefficients are in the region of $0 \cdot 9$, in spite of the necessarily rather crude methods of echo measurement.
\end{abstract}

* Ministry of Agriculture, Fisheries and Food. Fishery Investigations, Series II, 22, No. 9: Echo Sounding Experiments in the Barents Sea. By I. D. Richardson, D. H. Cushing, F. R. Harden Jones, R. J. H Reverton, and R. W. Blacker. Pp. vi +57. (London: H.M. Stationer
Oftice, 1959.) 20s. net.
In the past, much of the information required for systematic design of echo-sounders for fish detection has not been available. Design has been based largely on the properties of previous models known to give reasonably satisfactory results, followed by sea trials and alteretions as required. The third paper describes an attempt to obtain some of the necessary basic data. The echo strength given by (dead) cod of different lengths has been measured and compared with the echo given by a standard target, so that the target strength of the cod is known in absolute units. The water-borne noise has been measured as a function of ship-speed and water-depth (though unfortunately only in terms of received voltage without the sensitivity of the receiver being known). The information about the target strength of cod is of universal application, and that about the waterborne noise allows the prediction of the performance of this particular sounder over a wide range of conditions.

The checking of the performance of equipment under working conditions is highly desirable, and helps to give one confidence in both the equipment and one's methods. The first part of the fourth paper describes checks of the beam pattern and of the variation of echo-strength with depth. Such checks have been made on many other acoustic devices, and since in the present case they also agree with theoretical expectations within experimental accuracy, the fifteen pages devoted to this work seem excessive.

In conclusion, these papers describe a great deal of careful work, mostly 'in the field', and form a very valuable contribution to the subject.

M. J. TUCKER

\section{ORIGIN OF TEKTITES}

\author{
By Prof. H. C. UREY, For.Mem.R.S. \\ University of California, La Jolla
}

$\mathrm{L}$ AsT January, Dr. G. Baker ${ }^{1}$ criticized in considerable detail my suggestion ${ }^{2}$ that comet heads colliding with the Earth heated the surface to the melting point and spread small fragments of glassy objects to great distances and that these objects are tektites. I believe these objects have compositions which are not greatly different from some of the more acid terrestrial rocks, but that no source of sufficiently high temperatures to melt these materials is known to be present on the Earth's surface or somewhat below the surface. My communication was written to suggest a possible source of high temperatures. I really thought everyone who had worked on this problem would be pleased to consider a mechanism by which terrestrial material could be melted and scattered to great distances even though it did not necessarily answer all questions. This was certainly not true. I have thought over Dr. Baker's verr thoughtful criticisms and would like to make a brief roply.

Dr. Baker is quite right about tektites not being spaced some 50 million years apart in age, but Prof. Z. Kopal very soon pointed out to me that cometary collisions with the Earth were probably ten or more times as frequent as I had assumed. I have not troubled to correct this incorrect estimate, for it was very uncertain in any event. We probably have only the most approximate ideas in regard to the number of non-luminous comet heads moving in the solar system; and comet heads must certainly collide 